\title{
VOJAŠKA STRATEŠKA REZERVA IN TRANSFORMACIJA SODOBNIH OBOROŽENIH SIL
}

\author{
MILITARY STRATEGIC RESERVE AND THE \\ TRANSFORMATION OF MODERN ARMED FORCES
}

Povzetek V Sloveniji od sredine prejšnjega desetletja razvijamo koncept vojaške strateške rezerve, vendar se postavlja vprašanje glede njegove skladnosti s procesom transformacije sodobnih vojsk in glede izvedljivosti ter uporabnosti. Zaslediti je mogoče številne težave $\mathrm{z}$ vidika demografskega in širšega socialnega konteksta ter organizacijskega vidika. Zamisel o vojaški strateški rezervi ne sledi trendom količinskega in funkcionalnega preoblikovanja rezervnih sil, ki jih zasledimo v okviru širše transformacije sodobnih zahodnih vojsk. Z vidika značilnosti sodobnih konfliktov je učinkovitost zagotavljanja vojaške varnosti s konceptom vojaške strateške rezerve, ki temelji na naboru in mobilizaciji, vprašljiva. Nujna bi bila temeljita presoja ustreznosti koncepta vojaške strateške rezerve $z$ vojaškega vidika. V nasprotnem lahko pride do večanja razlik med deklariranimi in v resnici dosegljivimi cilji.

Ključne Rezervne sile, strateška rezerva, transformacija, Slovenska vojska, obrambno besede načrtovanje.

Abstract The development of the concept of Military Strategic Reserve in Slovenia can be traced back into the middle of the past decade. However, a question arises about its consistency with the transformation process in the modern armed forces as well as about its feasibility and efficiency. There are several problems from the viewpoint of demographic and broader social context as well as from the organisational viewpoint. The idea of military strategic reserve does not follow the trends of quantitative and functional restructuring of reserve forces present in the broader transformation of modern western armed forces. As far as the characteristics of contemporary conflicts are concerned, the effectiveness of providing military security with the concept of a conscription- and mobilisation-based military reserve is questionable. In order to prevent the widening of the gap between declared and attainable goals, it would be 
necessary to thoroughly assess the appropriateness of the military strategic reserve concept from a military point of view.

\section{Key words Reserve forces, strategic reserve, transformation, Slovenia Armed Forces, defence planning.}

Uvod Od začetka uvajanja množičnih vojsk v začetku 19. stoletja so te kot element svojih zmogljivosti razvijale tudi rezervno sestavo. Tudi sodobne zahodne, po večini poklicne, vojske razvijajo svojo rezervno komponento, vendar pa se ta po načinu organiziranosti in funkcijah razlikuje od rezervne komponente iz časov do konca hladne vojne. Spremembe vloge rezervne komponente vojsk so odraz geopolitičnih in družbenih sprememb ter sledijo zahtevam glede učinkovitosti vojsk v sodobnih razmerah. Takim razvojnim trendom sledi tudi Slovenska vojska (SV). Z odpravo služenja vojaškega roka leta 2003, uvedbo poklicnega popolnjevanja in manjše prostovoljne rezervne sestave, možnostjo prostovoljnega služenja vojaškega roka in leta 2010 tudi odpravo obvezne rezerve je Slovenija poskušala zagotoviti racionalno in učinkovito vojaško organiziranost. Tako obsežna transformacija vojske je korenito spremenila način zagotavljanja vojaške varnosti Slovenije in tudi vlogo vojske v družbi. ${ }^{1}$

Hkrati so od sredine prejšnjega desetletja prisotne zamisli o zagotavljanju vojaške strateške rezerve. Oblikovane so v dveh dokumentih, in sicer v Konceptu za oblikovanje vojaške strateške rezerve RS iz leta 2007 in v Doktrini vojaške strateške rezerve Republike Slovenije iz leta 2012 (v nadaljevanju doktrina VSR). S temi dokumenti Slovenija uveljavlja rešitev, ki do zdaj ni bila celovito ovrednotena $\mathrm{z}$ vidika zahtev, ki se postavljajo pred sodobne vojske, in z vidika učinkovitosti pri zagotavljanju obrambe države. ${ }^{2}$ Postavlja se vprašanje, kakšna je vloga omenjene zamisli v kontekstu širših transformacijskih procesov. Ne gre zanemariti tudi, da razvoj te zamisli poteka $\mathrm{v}$ kontekstu zmanjševanja pripravljenosti in razvojnega zaostajanja Slovenske vojske v zadnjem desetletju.

Koliko je zamisel o vojaški strateški rezervi skladna s trendom transformacije sodobnih vojsk in je učinkovita pri zagotavljanju obrambne sposobnosti države, lahko presojamo iz dveh zornih kotov:

a) iz zornega kota izvedljivosti, torej ali je naraščanje obsega SV, kot ga predvideva doktrina VSR, sploh izvedljivo v predvidenih rokih;

b) iz zornega kota uporabnosti, torej ali bi taka vojaška organiziranost v okviru groženj, ki si jih kmalu lahko predstavljamo, sploh lahko zagotovila učinkovito obrambo in opravljanje drugih nalog vojske.

\footnotetext{
V tem prispevku transformacijo razumemo v najširšem pomenu. Obsega spreminjanje organiziranosti, popolnjevanja, nalog in doktrine vojske, njenih odnosov s civilnim okoljem in položaja v družbi.

2 Podrobneje o razvoju in vsebini temeljnih dokumentov vojaške strateške rezerve glej Žnidaršič, 2016.
} 
Odgovore na ta vprašanja bom poskušal poiskati z vidika demografskega in socialnega konteksta, organizacijskega vidika, glede na skladnost koncepta VSR s sodobnimi trendi transformacije vojsk ter vidika značilnosti sodobnih konfliktov.

\section{DEMOGRAFSKI IN SOCIALNI KONTEKST}

Doktrina vojaške strateške rezerve predpostavlja precejšnje povečanje številčnega stanja SV v roku enega leta, in sicer za največ 25.000 pripadnikov, kar bi dosegli s ponovno uvedbo obveznega služenja vojaškega roka. Vzrok za tako odločitev bi bila poslabšanje varnostnih razmer in ogroženost pred vojaškim napadom. Prvo vprašanje, povezano z izvedljivostjo tega cilja, je, ali je res mogoče v letu dni pridobiti in usposobiti omenjeno število nabornikov. Pri analizi je treba upoštevati tako demografske kot tudi širše socialne dejavnike.

Ambicija usposobiti 25.000 posameznikov v roku enega leta pomeni z demografskega vidika angažiranje precejšnjega deleža mlade populacije. Predpostavljamo, da bi obvezno služenje vojaškega roka, ki bi bilo podlaga za tako usposabljanje, obseglo samo moško populacijo. $\mathrm{V}$ tabeli 1 vidimo, da letni kontingent moških, ki bodo dopolnili 18 let leta 2017, znaša 9049. Z višanjem starosti se sicer kontingenti nekoliko povečujejo, tako da med rojenimi leta 1990 delež moških znaša 11.454. $\mathrm{S}$ sedanje časovne perspektive torej lahko ocenimo, da razpoložljiv kontingent za vključitev v vojaško usposabljanje v populaciji mladih med 18 in 27 leti v vsakem letniku znaša med 9000 in 11.000 .

\footnotetext{
Tabela 1: Rojeni v Sloveniji v obdobju 1990-1999 Vir:

Statistični urad Republike Slovenije, http://pxweb. stat.si/pxweb/Dialog/viewplus. asp?ma=05A20 10S\&ti=\&path $=. . / \mathrm{Da}-$ tabase/Dem_soc/05_ prebivalstvo/05_ osnovni_podatki_ preb/10_05A20_prebivalstvo_letno/\& lang=2 (24. 8. 2017).
}

\begin{tabular}{|c|c|c|c|}
\hline Leto & Moški & Ženske & Skupaj \\
\hline 1990 & 11.454 & 10.914 & 22.368 \\
\hline 1991 & 11.116 & 10.467 & 21.583 \\
\hline 1992 & 10.333 & 9649 & 19.982 \\
\hline 1993 & 10.188 & 9605 & 19.793 \\
\hline 1994 & 9899 & 9564 & 19.463 \\
\hline 1995 & 9741 & 9239 & 18.980 \\
\hline 1996 & 9710 & 9078 & 18.788 \\
\hline 1997 & 9323 & 8842 & 18.165 \\
\hline 1998 & 9256 & 8600 & 17.856 \\
\hline 1999 & 9049 & 8484 & 17.533 \\
\hline
\end{tabular}


Pravo število posameznikov, razpoložljivih za vojaško usposabljanje, je, kot kažejo podatki iz preteklosti, precej manjše. Pri tem je treba upoštevati predvsem zdravstveno sposobnost za vojaško službo in možnost uveljavljanja ugovora vesti. Trenutnih podatkov o zdravstveni sposobnosti mladih za vojaško službo nimamo, ker tovrstno ocenjevanje ne poteka. Opremo se lahko na ocene iz preteklosti, ki kažejo precejšnje zmanjševanje zdravstvene sposobnosti: leta 1991 je bilo 84 odstotkov sposobnih za vojaško službo, leta 2002 le še 67 odstotkov. ${ }^{3}$ Če opustimo možnost, da je odstotek danes še manjši, ugotovimo, da pri 67-odstotni zdravstveni sposobnosti lahko razpolagamo s približno 6000 sposobnimi med tistimi, ki določenega leta dopolnijo 18 let. Možnost uveljavljanja ugovora vesti ta kontingent še precej zmanjša. O obsegu morebitnega uveljavljanja te možnosti prav tako ne moremo trdno sklepati, lahko pa se opremo na podatke iz preteklosti.

Uveljavljanje ugovora vesti se je od osamosvojitve Slovenije do odprave vojaške obveznosti zelo povečevalo. Leta 2001 je ugovor vesti uveljavljalo 3250 nabornikov, letni kontingent, napoten na služenje vojaškega roka, pa je v tem obdobju znašal približno 4500 posameznikov. Razmerje približno $1: 1,4$ med tistimi, ki so uveljavili možnost ugovora vesti, in tistimi, ki so služili vojaški rok v preteklosti, kaže, da bi bil sedanji letni kontingent tudi zato precej zmanjšan. Iz posameznega letnega kontingenta bi tako po približni oceni lahko računali na 3000 do 4000 posameznikov, ki bi lahko bili vključeni v vojaško usposabljanje ob sicer verjetni predpostavki, da se določila o izvajanju vojaške dolžnosti ne bi bistveno spremenila. ${ }^{4}$ Upoštevati je treba še dejstvo, da med služenjem vojaškega roka lahko pride do prekinitve zaradi zdravstvenih težav; v preteklosti je bilo takih primerov med 20 in 25 odstotki (Petrič, 2016, str. 238). Če pogledamo v prihodnost, bi morali upoštevati tudi dolgoročno zmanjševanje mlade populacije. V Sloveniji je leta 2016 delež mladih predstavljal 15,9 odstotka celotnega prebivalstva. V zadnjih petih letih (2011-2016) se je delež mladih zmanjšal za 2,4 odstotne točke. Skoraj enako je veljalo za celotno Evropsko unijo (Statistični urad RS, http://www.stat.si/StatWeb/News/Index/6799 (24. 8. 2017)).

Doseganje ambicioznega cilja usposobitve 25.000 posameznikov v letu dni bi tako zahtevalo hkraten vpoklic več letnikov. Pri udeležbi na primer 3500 posameznikov iz letnika bi bilo treba $\mathrm{v}$ roku enega leta na šestmesečno usposabljanje vpoklicati sedem letnikov, torej vse od 18. do 24. leta starosti. To bi pomenilo, da je v določenem obdobju velik delež najbolj sposobne mlade populacije izvzet iz šolanja in dela: tako tisti, ki bi opravljali vojaško usposabljanje, kot tudi tisti, ki bi jim po zakonodaji bilo treba omogočiti nadomestno civilno služenje vojaškega roka. Ne obstajajo ocene o vplivu tega na nacionalno gospodarstvo, gotovo pa bi bil ta pomemben.

Izhodišča MO RS glede možnosti ponovne uveljavitve obveznega služenja vojaškega roka.

4 Jelušič (2016, str. 156) v povezavi s tem opozarja, da bi Vlada in Državni zbor, če bi bilo treba, lahko začela izvajati vojaško obveznost, vendar ob tem ne bi mogla spregledati tistih členov Zakona o vojaški dolžnosti, $k i$ določajo ravnanje z oporečniki in zdravstveno nesposobnimi za služenje vojaškega roka. 
Poleg demografskih danosti na možnost izvajanja vojaške obveznosti in velikost nabornega kontingenta vplivata še splošni odnos javnosti in pripravljenost mladih za služenje vojaškega roka. Na tem področju lahko v zadnjih desetletjih opazimo precejšnje spremembe. Gre za splet širših socialnih dejavnikov. V tem kontekstu velja upoštevati Moskosovo (2000, str. 14-31) paradigmo prehoda iz moderne v postmoderno vojaško organizacijo. Opozarja, da se odnos javnosti do vojske spreminja od podpore v obdobju do konca druge svetovne vojne prek ambivalentnega (razdeljena in deloma kritična javnost) v hladni vojni do indiferentnega odnosa po njenem koncu. Nezanimanje in distanca javnosti do vojske in vojaških zadev v sodobnih družbah zahoda, na katere opozarja Moskos, sta v resnici težko združljiva z zamislimi o množični participaciji prebivalstva $\mathrm{v}$ vojaških zadevah. Haltiner in Szvircsev Tresch (2005, str. 294-299) pri obravnavi opuščanja nabora v evropskih državah opozarjata, da so poleg funkcionalnih vzrokov, kot so zmanjšanje vojaške ogroženosti in spremenjene naloge vojsk, k temu trendu prispevale tudi socialne spremembe $\mathrm{v}$ smeri pluralizacije življenjskih slogov in vrednostnih kultur. Individualizacija zmanjšuje pripravljenost za brezpogojno opravljanje obveznosti do države. Ugotavljata, da so v državah z liberalnimi vrednotami, v katerih so poudarjene vrednote posameznikovih pravic in svoboščin, precej laže odpravili nabor kot v državah, ki so bolj republikansko usmerjene.

Te splošne kulturno-socialne spremembe so pomembne tudi za razumevanje dogajanja v Sloveniji. Pri nas se je v preteklosti izrazito zmanjševala pripravljenost mladih za služenje vojaškega roka. Leta 1994 je bilo v Sloveniji na služenje napotenih 12.283 nabornikov; leta 2002 le še $4475 .{ }^{5} \mathrm{~K}$ velikemu zmanjšanju ni pripomoglo le zmanjšanje zdravstvene sposobnosti, temveč tudi drugi socialni dejavniki, ki so predvsem povečevali zanimanje za civilno služenje. Celovita analiza teh dejavnikov ni bila opravljena. Na splošno raziskave, izvedene prejšnje desetletje, potrjujejo navedene socialne spremembe. Malešič (2003) na podlagi raziskav, opravljenih v Sloveniji in tudi v tujini, opozarja na naslednje. Družbena sprejemljivost nabora se je v Sloveniji v začetku prejšnjega desetletja znašla v globoki krizi. K temu so poleg demografskih trendov prispevale tudi značilnosti postindustrijskih družb, kot so pluralizacija, individualizacija, specializacija in profesionalizacija. Malešič opozarja tudi na dejstvo, da se v zahodnoevropskih državah kaže, da se sicer široka javna podpora vojaštvu in zaupanje $v$ to institucijo ne kažeta $v$ pripravljenosti ljudi za sodelovanje v vojski. Opozarja na vpliv sprememb na področju vrednot med mladimi:

»Za mlado generacijo ... so postmaterialistične (postmoderne) vrednostne orientacije vedno bolj pomembne. Te orientacije se odražajo v tendenci mladih ljudi za umik v zasebno življenje in v nizkem zaupanju v politične in represivne institucije države. Predpostavljamo, da je v Sloveniji velik delež mladih s postmaterialističnimi vrednostnimi orientacijami nagnjen k izogibanju vojaške službe, medtem ko mladi

5 Izhodišča MO RS v zvezi z možnostjo ponovne uveljavitve obveznega služenja vojaškega roka. 
z materialističnimi in bolj konservativnimi političnimi orientacijami kažejo večji interes za vojsko in vojaške zadeve ...« (Malešič, 2003, str. 179).

Isti avtor tudi opozarja na spremenjene poglede javnosti glede popolnjevanja vojske. Raziskava v Sloveniji leta 2001 je namreč pokazala precejšnje povečanje podpore poklicni vojski (48 odstotkov), medtem pa se je zmanjšala podpora vojaški obveznosti na 34 odstotkov. Zamisel o poklicni vojski je v Sloveniji tako postala precej splošno sprejeta. V takem kontekstu obstaja vprašanje, kako bi bila V slovenski družbi v prihodnje sprejeta vojaška obveznost, čeprav bi šlo za povečano vojaško ogroženost.

Splošno legitimnost služenja vojaške obveznosti skupaj s pripravljenostjo mlade generacije je upravičeno razumeti kot pomemben dejavnik vpliva na možnosti doseganja ciljev, zapisanih v doktrini VSR. Vprašljivoje, kolikojemogoče zmanjševati obseg doseženih svoboščin posameznika oziroma uvajati nove obveznosti, pa čeprav zaradi varnosti. ${ }^{6}$ Tudi med strokovnjaki s področja varnosti in obrambe pri nas je mnenje, da bi bila po zmanjšanju obsega vojsk in uvajanju poklicnega modela, kar se je zgodilo v večini evropskih držav, vrnitev v preteklost izjemno težavna in možna le ob neposredni in veliki vojaški ogroženosti države (Svete, 2016, str. 69). Upravičeno je tudi vprašanje, ali bi neposredna vojaška ogroženost imela za posledico povečano podporo vojaški obveznosti. S prehodom na poklicno vojsko je javnost precej sprejela tudi zamisel, da je obramba dolžnost poklicnih vojakov. Tako razmišljanje potrjujejo tudi raziskave med mladimi v Sloveniji. ${ }^{7}$

Zamisel o vojaški strateški rezervi temelji na predpostavki, da bo mogoče uporabiti model popolnjevanja vojske iz preteklosti, ki je v zahodnem svetu zagotavljal popolnjevanje množičnih vojsk. Ta je temeljil na odnosu med državljanom in državo, bil vzpostavljen z nastajanjem nacionalnih držav od začetka 19. stoletja in je zagotavljal, da lahko država s svojo avtoriteto in tudi prisilo vojski zagotovi zadostno število pripadnikov. V sodobnosti se spreminjajo vloga in avtoriteta države, pravice, interesi ter vrednote posameznika in odnos med posameznikom in državo. To upoštevajo koncepti popolnjevanja vojsk v sodobnih zahodnih državah, ki se v kontekstu transformacije vojsk spreminjajo. Slovenski model VSR ob siceršnji transformaciji SV v smeri sodobne vojske temelji na načinu popolnjevanja, ki je bil uveljavljen v preteklosti in ga v sodobnih vojskah opuščajo. Izvedljivost takega pristopa je zelo vprašljiva, prav tako pa njegova učinkovitost pri zagotavljanju vojaške obrambe.

\footnotetext{
- Kar se v sodobnosti kaže tudi skozi vprašanje zmanjševanja svoboščin posameznika v okviru tako imenovanega boja proti terorizmu. Sodobni terorizem je sicer stalno prisotna grožnja in upravičuje določeno zmanjševanje svoboščin v smislu vzpostavljanja nadzora, vendar je to privedlo tudi do težave razmerja med svobodo in varnostjo.

Prebilič in Juvan (2014, str. 73) navajata rezultate raziskave, ki kažejo, da je le 27 odstotkov srednješolcev pripravljenih braniti domovino, kar pojasnjujeta s pristnostjo razmišljanja v sodobni družbi, da naj »obrambo domovine opravijo tisti, ki so za to plačani in usposobljeni«.
} 


\section{ORGANIZACIJSKI VIDIKI UVELJAVLJANJA VOJAŠKE STRATEŠKE REZERVE}

Opozoriti je treba tudi na tveganja glede izvedljivosti ciljev doktrine VSR na organizacijski ravni. Nedorečenost rešitev, ki jih ponuja doktrina, tudi tuji analitiki štejejo med pomanjkljivosti obrambnega načrtovanja v Sloveniji. Young (2016, str. 30) opozarja na namen, da bi izurili in opremili 25.000 nabornikov v roku enega leta, pri čemer se postavlja vprašanje, kje dobiti infrastrukturo, izvajalce usposabljanja in opremo. Upoštevati moramo tudi težave, s katerimi se SV nenehno srečuje pri transformaciji. Če k temu dodamo še razvojno zaostajanje zaradi zmanjšanja finančnih sredstev, ki je posledica krize po letu 2009, se zdijo omenjena tveganja še večja.

Ob precejšnjem povečanju osebja na usposabljanju bi se SV srečala z nekaj resnimi težavami. Po letu 2003, ko je bilo odpravljeno služenje vojaškega roka, so se precej zmanjšale zmogljivosti SV glede nameščanja in oskrbe v vojaških objektih. ${ }^{8}$ Težave bi nastale tudi zaradi premalo vadišč in strelišč ter častniškega in podčastniškega kadra, ki bi izvajal usposabljanje. SV v sedanji sestavi nima odvečnega kadra za te dodatne naloge. $\mathrm{V}$ doktrini ni jasnih odgovorov glede zagotovitve tovrstnega kadra. Predvideno je, da naj bi se del izvajalcev usposabljanja VSR pripravljal v okviru MO in SV že v miru (Doktrina vojaške strateške rezerve Republike Slovenije, 2012, str. 16), kar do zdaj ni bilo realizirano, vključevali pa naj bi tudi akterje iz drugih okolij, vendar o razpoložljivosti in strokovni ustreznosti slednjih lahko močno dvomimo. ${ }^{9}$ Take rešitve bi nujno privedle do znižanja zahtev, ki jih morajo izpolnjevati izvajalci usposabljanja. ${ }^{10}$ To bi pomenilo nizko raven usposobljenosti vpoklicanih pripadnikov in posledično njihovo vprašljivo uporabnost.

Vprašljiva bi bila tudi opremljenost z vadbenimi sredstvi, opremo in oborožitvijo, vsekakor pa bi bila slabša kot pri pripadnikih stalne sestave, čeprav doktrina predvideva enake standarde. ${ }^{11}$ Vzpostavitev VSR naj bi namreč v materialnem smislu temeljila na strateški rezervi oborožitve in opreme, ki je izločena iz operativne uporabe SV (Doktrina vojaške strateške rezerve Republike Slovenije, 2012, str. 13)

\footnotetext{
S težavami zadostnih namestitvenih možnosti se je SV srečala že ob razmisleku, da bi usposabljanje pripadnikov prostovoljne pogodbene rezerve, ki je leta 2016 potekalo na dveh lokacijah, in sicer v Vipavi in Novem mestu, začeli izvajati na več lokacijah v Sloveniji, s čimer bi kraj usposabljanja približali bivališčem pripadnikov.

9 Doktrina predvideva povečano vlogo društev in nevladnih organizacij, ki delujejo v javnem interesu na področju obrambe, in da se vizvedbo usposabljanj vključijo tudi upokojeni podčastniki, častniki in nekdanji pripadniki mirnodobne strukture SV in, če je treba, tudi inštruktorji iz držav članic Severnoatlantskega zavezništva in partnerskih držav (str. 16 in 21).

I0 V miru velja, da morajo izvajalci usposabljanja v SV dosegati zelo zahtevna merila tako glede stroke kot didaktičnih kompetenc. Pred usposabljanji se redno izvajajo tudi tečaji za izvajalce in inštruktorje, andragoška izobraževanja ipd.

${ }^{\prime \prime}$ "Pripadniki, ki se bodo vključili v operativne enote SV po aktiviranju koncepta VSR, morajo biti z vidika svoje opremljenosti, usposobljenosti in pripravljenosti primerljivi s pripadniki mirnodobne sestave $S V$...« (doktrina, 2012, str. 11).
} 
in je torej navadno zastarela. ${ }^{12}$ Glede pridobivanja materialnih sredstev sta predvideni tudi »razporejanje sredstev iz popisa«, torej iz civilnih virov, ter opremljanje z novo oborožitvijo in opremo (Doktrina vojaške strateške rezerve republike Slovenije, 2012, str. 14). Iz civilnih virov bo najbrž težko pridobiti sredstva, uporabna za SV. Taka praksa bolj spominja na nekdanjo Teritorialno obrambo, ki je tako vozila in nekatera druga sredstva pridobila tudi od posameznikov in civilnih organizacij. O uporabnosti takih rešitev pri sodobnih vojskah in $\mathrm{v}$ spremenjenih družbenih razmerah lahko močno dvomimo. Tudi nakup nove opreme in oborožitve lahko glede na dolgotrajnost teh postopkov pomeni precejšen časovni zamik pri doseganju postavljenih ciljev.

Neustrezna opremljenost in nizki standardi usposabljanja lahko povratno vplivajo na odziv ter motiviranost obveznikov za usposabljanje. Če je usposabljanje namenjeno tudi poznejšemu oblikovanju vojaških enot, je treba izobraževati in usposabljati še dodatni podčastniški in častniški kader, kar pa v opredeljenem roku enega leta ni izvedljivo. ${ }^{13}$ Ocenimo lahko, da ob sedanjih infrastrukturnih, logističnih in kadrovskih zmožnostih cilji doktrine VSR v predvidenem roku ne bi bili doseženi.

Med tveganja glede izvedljivosti ciljev doktrine lahko uvrstimo tudi možnost pravočasnega sprejetja potrebnih odločitev na državni ravni. Doktrina glede uveljavitve VSR predpostavlja, da »ob izrazitem poslabšanju mednarodnih varnostnih razmer in na podlagi ocene ogroženosti države pred napadom Vlada RS sprejme predlog aktivnosti za povečanje obrambnih sil države in ga posreduje v obravnavo v Državni zbor« (Doktrina vojaške strateške rezerve Republike Slovenije, 2012, str. 10). Iz te predpostavke lahko razberemo, da postopek za začetek aktivnosti obsega najprej identifikacijo groženj, ki bi zahtevale tako ravnanje, $\mathrm{v}$ nadaljevanju pa ustrezne aktivnosti na ravni sprejemanja politične odločitve. Glede na značilnosti sodobnih konfliktov in drugih varnostnih groženj lahko dvomimo o možnosti pravočasnega sprejetja ustreznih odločitev. Danes je zaznavanje jasne ogroženosti pred napadom oziroma vojaških groženj zelo oteženo. Razlike med vojno in mirom se v sodobnih konfliktih zabrisujejo, ${ }^{14} \mathrm{~s}$ čimer se, kot to imenuje Zapfe (2015, str. 2), ustvarja »strukturna siva cona« v odnosih med državami. Večino sedanjih in najbrž tudi prihodnjih konfliktov ni mogoče uvrstiti v tradicionalno kategorijo »vojne«. Thornton (2015, str. 3) tovrstne konflikte poimenuje $»$ nejasno vojskovanje« (angl. ambiguous warfare). Vse bolj pomembna sta uporaba nevojaških sredstev in prikrito izvajanje aktivnosti, kar danes pogosto označimo tudi kot »hibridno vojskovanje«. Svoje strateške cilje lahko napadalec

\footnotetext{
12 Tudi Obrambna strategija podobno navaja, da bodo neperspektivni oborožitveni sistemi izločeni iz uporabe in nekateri lahko namenjeni vojaški strateški rezervi (Obrambna strategija RS, 2012, str. 37).

13 Šteiner (2016a, str. 80) ocenjuje, da bi za dodatno strukturo 25.000 vojaških oseb potrebovali 2000 častnikov in 5000 podčastnikov. Glede na sedanje stanje je to dvakrat več častnikov in dvainpolkrat več podčastnikov, kot jih je v SV, oziroma, če vzamemo razmerje med častniki, podčastniki in vojaki $1: 2: 5$, kot velja za sodobne vojske, to $v$ strukturi 25.000 pripadnikov pomeni 3125 častnikov, 6250 podčastnikov in 15.625 vojakov.

${ }^{14}$ Podrobneje o teh spremembah piše Potočnik (2016) v kontekstu razprave o četrti generaciji vojskovanja.
} 
doseže že pred uporabo vojaške sile ali pa sploh brez nje. Pri tem si navadno prizadeva za paraliziranje pomembnih infrastrukturnih in družbenih sistemov.

V sodobnosti smo tudi priče nenadnemu pojavu in hitremu stopnjevanju konfliktov. V strateškem smislu gre pogosto za presenečenja. Primeri so iraška okupacija Kuvajta in zalivska vojna leta 1991, tako imenovana arabska pomlad leta 2011 in hibridna vojna Rusije proti Ukrajini leta $2014 .{ }^{15}$ O tem, da se predvidljivost glede prihodnosti zmanjšuje, kažejo tudi Natova predvidevanja glede možnosti hitrih in korenitih sprememb strateškega okolja, kar imenujejo tudi »strateški šoki« (SFA, 2013, str. 7). Če upoštevamo vse navedeno, bi z ukrepanjem, kot je predvideno z doktrino VSR, zelo težko pravočasno in ustrezno odgovorili na vojaške grožnje. Problematična bi bila že presoja o tem, kdaj je grožnja dovolj realna in intenzivna, da je treba uvesti predvidene ukrepe.

Drugi kritični element je lahko doseganje političnega soglasja v državi. Glede ponovne uvedbe nabora in drugih ukrepov iz doktrine VSR bi odločal Državni zbor, pri čemer bi bilo potrebno soglasje najpomembnejših političnih strank. To je lahko, posebej v razmerah, ko je težko oceniti intenzivnost grožnje, dolgotrajen in negotov proces. Predvidevanja glede procesa odločanja so tvegana, vendar lahko, kot kaže preteklost, pričakujemo različna stališča političnih strank do temeljnih obrambnih vprašanj in tudi do morebitne vojaške obveznosti v prihodnje. Kot je pokazala raziskava iz začetka prejšnjega desetletja, katere rezultate povzema Malešič (2003, str. 177-178), sta večina parlamentarnih strank in tudi vladajoča koalicija podpirali postopen prehod k poklicni vojski. Razlike so bile v tem, da so nekatere stranke podpirale ukinitev splošne vojaške obveznosti, druge pa bi jo ohranile v trenutni obliki ali kot možnost prostovoljnega služenja. Že hipotetična verjetnost, da bi med političnimi strankami obstajala različna stališča do ponovne uvedbe nabora, kaže, da bi doseganje ciljev doktrine VSR lahko bilo negotovo.

Pri sprejemanju politične odločitve in izvajanju aktivnosti za uveljavitev ukrepov doktrine VSR so se spoprijemali še z drugimi težavami. Ob zaostrovanju razmer vsak akter poskuša ovirati obrambna prizadevanja svojega nasprotnika. Ta značilnost skoraj vseh vojn je še posebno izrazita v sodobnih konfliktih, ki jih opisujemo kot »hibridne vojne«, vojne četrte generacije ipd. ${ }^{16}$ Odkrito grožnjo in uporabo sile zamenjujejo osredotočenost na slabitev družbene kohezivnosti žrtve, potenciranje notranjih družbenih in političnih nasprotij, vzbujanja nezadovoljstva z oblastmi idr., vse z intenzivnim propagandnim delovanjem $\mathrm{v}$ javnem mnenju in s prikritimi

\footnotetext{
${ }^{15}$ V Ukrajini so se razmere zaostrile po odstavitvi prorusko usmerjenega predsednika konec februarja 2014, marca je prišlo do ruske zasedbe polotoka Krim, aprila pa do razglasitve samostojnih republik Donetsk in Lugansk in oboroženih spopadov na vzhodu Ukrajine.
}

\footnotetext{
${ }^{16}$ Avtorji koncepta četrte generacije vojskovanja spremembe med drugim vidijo v disperziranju bojišča, ki bo verjetno obsegalo celotno družbo nasprotnika, v prizadevanjih notranje zlomiti nasprotnika brez fizičnega uničenja ter v zabrisovanju razlike med mirom in vojno (Lind, 1989, str. 23).
} 
oblikami delovanja. ${ }^{17}$ To pomeni, da bi lahko poslabšanje varnostnih razmer, kar bi sicer zahtevalo aktivnosti vzpostavitve VSR, prineslo tudi aktivno delovanje proti državi, kar bi oteževalo izvedbo teh aktivnosti, še posebno, ker te aktivnosti ne obsegajo le nabora in usposabljanja posameznikov, temveč imajo tudi materialnofinančne, komunikacijske, logistične in moralne dimenzije.

\section{REZERVNE SILE IN TRANSFORMACIJA}

Zadnjega četrt stoletja smo bili priča strateškim spremembam, ki so bile precej univerzalne in so preobrazile večino vojsk v zahodnem svetu. Tudi v Sloveniji so privedle do pomembnih sprememb na področju vojske. Te so potekale v kontekstu novih geopolitičnih razmer, ki so privedle do zmanjševanja obsega vojsk, novih nalog v ohranjanju mednarodnega miru, do odprave vojaške obveznosti, ki je zagotavljala kadrovsko bazo za množične vojske, in do drugega. Kako so se v Evropi navedene spremembe pokazale na obsegu vojsk in razmerju med stalnimi in rezervnimi vojaškimi silami, nam pokažejo podatki iz tabele 2 . V primerjavo so vključene sosednje države, Češka in Slovaška kot Sloveniji delno primerljivi državi novi članici Nata ter tri vojaško najmočnejše evropske države. V opazovanem obdobju 20 let pri vseh ugotovimo skoraj enake spremembe.

\begin{tabular}{|c|c|c|c|c|c|}
\hline \multirow{11}{*}{$\begin{array}{r}\text { Tabela 2: } \\
\text { Obseg vojaških sil } \\
\text { v izbranih državah } \\
(1995-2014) \\
\text { Vir: } \\
\text { Military Balance } \\
\text { 1995/96 in 2015. }\end{array}$} & \multirow[t]{2}{*}{ Država } & \multicolumn{2}{|c|}{ Skupni obseg vojaških sil leta 1995} & \multicolumn{2}{|c|}{ Skupni obseg vojaških sil leta 2014} \\
\hline & & Rezervne sile ${ }^{18}$ & Stalne sile & Rezervne sile & Stalne sile \\
\hline & Avstrija & 119.000 & 55.750 & 24.400 & 22.500 \\
\hline & Madžarska & 173.000 & 70.500 & 44.000 & 26.500 \\
\hline & Hrvaška & 180.000 & 105.000 & 0 & 16.500 \\
\hline & Italija & 304.000 & 328.000 & 18.300 & 176.000 \\
\hline & Slovaška & 0 & 47.000 & 1500 & 7600 \\
\hline & Češka & 0 & 86.400 & 0 & 21.000 \\
\hline & Nemčija & 414.700 & 339.900 & 45.000 & 181.000 \\
\hline & Francija & 337.300 & 409.000 & 27.650 & 215.000 \\
\hline & Velika Britanija & 262.900 & 236.900 & 79.100 & 159.100 \\
\hline
\end{tabular}

${ }_{17}$ Take aktivnosti poznamo tudi kot subverzivno delovanje. Nazoren primer je na primer ruska politika do Evrope, obsega pa podporo protievropskim desnim strankam v članicah EU, umerjenost na delovanje med rusko manjšino oziroma »rojake v tujini $v$ državah, $v$ katerih živijo, in ruska prizadevanja za zmanjševanje kohezivnosti Nata (več o tem v Thornton, 2015, str. 13-15, in Zapfe, 2015).

${ }^{18}$ Upoštevano je število pripadnikov, razpoložljivih za takojšnjo mobilizacijo (za te se ponekod uporablja tudi izraz »regular reserve"). Ponekod zasledimo tudi višje številke, ki so v času vojaške obveznosti obsegale vso vojaško usposobljeno populacijo do določene starosti, vendar je z vidika uporabnosti pomembnejši obseg dejansko razpoložljive rezerve. 
Takoj po hladni vojni so v večini prikazanih držav rezervne sile številčno presegale stalno sestavo. ${ }^{19}$ Dvajset let pozneje je stanje povsem drugačno. Skupni obseg vojaških sil držav se je precej zmanjšal, bistveno pa se je spremenilo tudi razmerje med stalno sestavo in rezervo. Rezervne sile so zdaj bistveno manjše od stalne sestave. Izjemi sta Madžarska in Avstrija, ki ima razmerje približno uravnoteženo. Spremembe jasno kažejo odpravo množičnih vojsk, ki so bile precej odvisne od mobilizacije rezervnih sil. Poleg kvantitativne spremembe pa je zaznati tudi trend funkcionalne integracije rezervnih sil s stalno sestavo. To pomeni tudi povečevanje sposobnosti skupnega delovanja obeh komponent, zaradi česar morajo biti rezervne sile bolje opremljene, izurjene in pripravljene. Primer take integracije lahko najdemo v britanski kopenski vojski, v kateri s programom Army 2020 še zmanjšujejo obseg rezerve (cilj je 82.000 pripadnikov stalne sestave in 30.000 rezerve) ter krepijo njeno vlogo v vseh vrstah operacij, tudi v tujini. Rezervne sile so vključene v vse vrste sil ne glede na njihovo vlogo in stopnjo pripravljenosti. ${ }^{20}$ To zahteva dvig usposobljenosti in kakovostno urjenje, ki mora potekati tudi skupaj s stalno sestavo (Transforming the British Army, 2013). Tudi primeri drugih držav kažejo, da rezervne sile postajajo komplementarne s stalno sestavo pri opravljanju številnih nalog, vključno $\mathrm{z}$ operacijami $\mathrm{v}$ tujini (Lasconjarias, 2013, str. 2). Funkcija rezerve torej ni več bistveno povečanje obsega vojske z mobilizacijo, temveč dopolnjevanje stalne sestave glede na funkcionalne potrebe. ${ }^{21}$ Pri tem se veča pomen usposobljenosti in pripravljenosti rezerve. Za tako rezervo ponekod uporabljajo tudi izraz aktivna rezerva (angl. active reserve) ali pripravljena rezerva (angl. ready reserve).

Spremembo vloge rezerve v sodobnih vojskah lahko vidimo predvsem v tem, da se ob stalni sestavi razvija manjša rezervna sestava, ki pa se glede na pripravljenost približuje standardom stalne sestave. Večina vojsk ohranja tudi rezervne sile, vendar so te manjše, dobro izurjene in opremljene ter sposobne skupnega delovanja s stalno sestavo vojske v vseh okoljih in nalogah. Konec množičnih vojsk je privedel tudi do konca množičnih rezerv, ki jih ne nazadnje ni več mogoče vzdrževati zaradi odprave vojaške obveznosti, ki je zagotavljala usposobljen rezervni kader. Kot ugotavlja Dunnigan (2003, str. 139), se sistem rezerve, kakršen se je razvil v 19. stoletju, da bi zagotavljal množično pehoto, danes obravnava kot neproduktiven. Množičnost danes ob obstoju visokotehnoloških orožij ne zagotavlja več učinkovitosti.

V Sloveniji smo s spremembami po uvedbi poklicne vojske v glavnem sledili tem trendom. V temeljnih usmerjevalnih dokumentih je zapisan cilj doseganja največjega številnega stanja SV 10.000 pripadnikov s ciljnim razmerjem med pripadniki stalne sestave in pripadniki prostovoljne pogodbene rezerve $4: 1$; torej 8000 proti 2000 (ReSDPROSV25, 2010). V ustreznih planskih dokumentih so bile te ambicije

\footnotetext{
19 Izjema sta Češka in Slovaška, ki sta se rezervi odpovedali takoj po koncu hladne vojne.

${ }^{20}$ Rezervne sile so predvidene v strukturi vseh treh vrst sil in bodo delovale v vseh vrstah operacij. Sile delijo na sile za posredovanje (reaction force), ki so v najvišji pripravljenosti, rezervne sile tu predstavljajo manjši delež, bolj pa so zastopane $v$ prilagodljivih silah (adaptable force), ki opravljajo različne naloge, in rodovskih silah (force troops), namenjenih za podporo delovanja (artilerija, zveze, logistika).

${ }^{21}$ O spreminjanju vloge in značaja rezerve glej tudi v Šteiner, 2016, posebej str. 175-178.
} 
nekoliko zmanjšane na 7600 pripadnikov stalne sestave in 1500 pripadnikov prostovoljne pogodbene rezerve (SOPR 2016-2020), vendar je bilo ohranjeno razmerje med sestavinama. Zamisel o VSR prinaša $\mathrm{v}$ poglede na vlogo in razvoj SV novo dimenzijo. V Sloveniji naj bi, če bi bilo treba, mobilizirali skoraj triinpolkrat večjo sestavo, kot je stalni obseg SV. Zamisel kaže na revitalizacijo koncepta vojske, ki temelji na množičnosti in mobilizaciji ter ki je bil v zahodnih vojskah v zadnjih dveh desetletjih odpravljen. Ali bi s takim konceptom lahko zagotovili ustrezen odziv ob vojaških grožnjah Sloveniji ali zavezništvu, katerega članica je?

Temeljni cilj transformacije je zagotavljati učinkovito vojsko. Sodobno varnostno okolje in narava vojne postavljata okvire učinkovitosti. Za varnostno okolje so značilni nepredvidljivost, možnost hitrih sprememb, težavnost vnaprejšnjega prepoznavanja varnostnih groženj in drugo. Iz narave vojne nasploh, še posebej sodobnih, izhaja težnja za doseganje hitre zmage. Napadalec se navadno želi izogniti dolge in izčrpavajoče vojne, ki prinaša dodatna bremena. Prizadeva si tudi za politiko izvršenih dejstev (načelo »fait accompli«), s katero se cilji dosežejo hitro in ki onemogoča nadaljnji odpor, zato je pomembna sposobnost hitrega odzivanja, ki se na primer odraža tudi v politiki Nata, njegov odzivni čas pa se skrajšuje.22 To določa potrebo po silah, ki so sposobne takojšnjega delovanja. Vojska vedno opravlja tudi funkcijo odvračanja, to pa je lahko učinkovito le, če je kredibilno. Kot ugotavlja Gerson (2009, str. 42), je kredibilnost funkcija ocene nasprotnika o vojaški zmogljivosti države žrtve in njeni politični odločenosti. Odvračanje je vplivanje na namere nasprotnika tako, da ga s tem odvrnemo od nasilnih dejanj. Pri tem štejejo predvsem trenutne zmogljivosti in s tega vidika morebitna možnost vzpostaviti vojsko v dolgem roku ni kredibilen dejavnik odvračanja. Navedeno kaže, da je za neposredno zagotavljanje vojaške varnosti države kot tudi za delovanje v okviru operacij Nata pomembno predvsem, da ima država sile, ki jih je mogoče takoj uporabiti. Razvijanje vojaških zmožnosti, ki je zamišljeno kot postopno naraščanje sil v odgovor na nastanek konkretnih varnostnih groženj, ne zagotavlja odvračanja niti učinkovite vojaške obrambe.

Učinkovitost koncepta VSR je mogoče problematizirati tudi zaradi nejasnega končnega stanja, ki naj bi bilo tako vzpostavljeno. Deklarirani cilj koncepta je vzpostavljanje operativnih zmogljivosti, ${ }^{23}$ vendar obravnava le usposabljanje posameznikov oziroma služenje vojaškega roka, brez koncepta strukture rezervnih enot, ki bi se oblikovala po končanem usposabljanju. ${ }^{24}$ Vojaško zmogljivost lahko

\footnotetext{
${ }^{22}$ Kot zavezništvo ugotavlja v svojih dokumentih, »se krize lahko razvijejo tako hitro, da ne bo zadostnega časa za tradicionalni proces odločanja, če naj bi zagotovili pravočasen odziv« (FFAO 2015, str. 13). Leta 2004 je Nato oblikoval strukturo NRF, ki bi jih bilo v roku 30 dni mogoče uporabiti za hitro posredovanje v krizah. Leta 2015 pa je to nadgradil s strukturo VJTF (tako imenovana Spearhead Force), ki bi jo bilo mogoče namestiti v dveh do petih dneh.

${ }^{23}$ V doktrini zapisan cilj koncepta VSR je, da se najpozneje v letu dni po aktiviranju VSR z izvajanjem vojaške in drugih obrambnih dolžnosti dosežejo operativne zmogljivosti SV v obsegu do dodatnih 25.000 pripadnikov (doktrina VSR, str. 17).

${ }^{24}$ Podobno tudi Kukec (2016, str. 146) ugotavlja, da v doktrini VSR manjkajo stališča o strukturi SV po aktiviranju rezerve, ki so potrebna za uresničenje njene vloge $v$ zagotavljanju zmožnosti za delovanje.
} 
predstavljajo šele posamezniki, ki so ustrezno organizirani v vojaške enote, te pa razpolagajo z vsemi potrebnimi materialnimi in nematerialnimi elementi. Napačno bi bilo misliti, da povečanje števila vojaško usposobljenih državljanov v družbi že pomeni tudi večjo vojaško zmogljivost oziroma obrambno sposobnost. V resnici ta problematika ni nova in smo jo poznali že v letih, ko je potekalo še obvezno vojaško služenje. Malešič (2003, str. 176) med težavami, povezanimi z naborom, navaja tudi dejstvo, da je kratek vojaški rok (sedem mesecev) obsegal samo temeljno vojaško usposabljanje, kontingent nabornikov pa ni prispeval $\mathrm{k}$ bojnim zmogljivostim oboroženih sil. Ugotovimo lahko, da doktrina VSR obravnava samo prvo in mogoče najmanj problematično fazo oblikovanja vojaških zmogljivosti. Nadaljnji koraki, ki zahtevajo organiziranje, opremljanje in usposabljanje enot, niso obravnavani, vemo pa, da so to zahtevni in dolgotrajni procesi.

Oblikovanje vojaških sil z mobilizacijo lahko poteka različno. Lahko je vpoklic že oblikovanih in izurjenih enot ali vpoklic novincev, ki šele morajo opraviti temeljno vojaško urjenje, kar je bistveno daljši proces. Na te razlike opozarja na primer Dunnigan, ki meni, da je iz usposobljenih rezervistov ob ustrezni opremljenosti in spodbudah mogoče oblikovati vojaške enote v nekaj mesecih, iz »nič« oziroma brez usposobljenega moštva pa to traja 365 dni (povzeto po Podvršnik, Pograjc, 2016, str. 112). Opozorilo ni nepomembno, čeprav se mogoče z navedenimi roki ne moremo v celoti strinjati. V Sloveniji je število posameznikov z odsluženim vojaškim rokom danes zanemarljivo - vsaj med populacijo do 30. leta. Veliko večino novih pripadnikov SV bi bilo treba usposobiti povsem od začetka. Služenje vojaškega roka zelo verjetno ne bi bilo daljše od šestih mesecev, kot je opredeljeno z zakonom, in bi omogočilo le osnovno usposobljenost, ni pa jasno, kako in kdaj bi poleg tega izvedli tisto fazo oblikovanja rezerve, v kateri se oblikujejo operativne zmogljivosti. Navedeno skupaj z že naštetimi težavami glede infrastrukture, opreme in zagotavljanja poveljniškega kadra kaže, da bi vzpostavljanje operativnih vojaških zmogljivosti zahtevalo precej daljši rok, kot predvideva doktrina VSR.

\section{VOJAŠKA STRATEŠKA REZERVA IN SODOBNI KONFLIKTI}

Uporabnost VSR je smiselno presojati tudi z vidika odgovora na vprašanje, ali bodo konflikti v prihodnje sploh zahtevali množično vojsko, ki bo temeljila na vojaški obveznosti in množični rezervi. V razmerah po hladni vojni se je uporabnost takih vojsk močno zmanjšala. Kot ugotavlja Malešič (2003a, str. 191), po hladni vojni učinkovito opravljanje novih nalog vojske, ki so predvsem v mednarodnem kontekstu, zahteva mobilne, fleksibilne in modularne oborožene sile, ki lahko ponudijo različne odzive na kompleksne krize. To stanje ne dopušča državam, da bi se opirale na učinkovitost in kredibilnost izključno ali pretežno naborniških oboroženih sil. Žabkar (2005, str. 134-136) ugotavlja, da po hladni vojni obstaja soglasje, da za obrambo Evrope ne bodo več potrebne nekdanje množične oborožene sile, niti še bolj množične rezervne enote. Opozarja, da je posledično v razvitih državah prišlo do popolne ali delne opustitve paradigme državljana vojaka, njegovo vlogo pa so danes prevzeli poklicni vojaki. 
Prihodnost je sicer nepredvidljiva, zato jasnih odgovorov glede nalog vojsk in njihove strukture $\mathrm{v}$ prihodnosti ni mogoče dati. ${ }^{25} \mathrm{Kljub}$ temu lahko na podlagi razpoložljivih analiz ugotovimo temeljne trende glede vojskovanja $\mathrm{v}$ prihodnje. Pomembne spremembe $\mathrm{v}$ kontekstu sodobnega vojskovanja, kot jih navaja Gray (2010, str. 11-12), so: vojne bodo obsegale tudi kibernetične dimenzije in vojskovanje v vesolju; razvoj globalnih medijev bo vzpostavljal kulturno-moralni nadzor nad delovanjem; visoka tehnologija, ki bo temeljila na informatizaciji, bo dostopna tudi nedržavnim akterjem in »šibkim« državam; materialno šibkejši udeleženci vojn bodo šibkost nadomeščali z asimetričnimi strategijami. V Natovih analizah glede prihodnjega okolja operacij ugotavljajo, da bodo spremembe glede prihodnjega značaja konfliktov obsegale hiter nastanek in eskalacijo oboroženih konfliktov; medsebojno povezanost prostora vojskovanja (vesolje, zrak, kopno, morje in kibernetski prostor); hiter razvoj tehnologij na področjih, kot so kibernetika, avtomatizacija, umetna inteligenca idr.; manjša bo številčnost vojaških sil, ki pa se lahko vojskujejo na večjih razdaljah (FFAO Workshop, 2016).

Poleg splošnih trendov, ki nakazujejo značilnosti vojskovanja v prihodnosti, je upravičen tudi razmislek o posledicah geopolitičnih sprememb v evro-atlantskem prostoru. Geopolitična konfrontacija na vzhodu Nata in povečanje pomena njegove obrambne drže v zadnjih letih postavljajo tudi vprašanje glede nalog in značaja vojsk. Odzivi v zavezništvu na te spremembe se kažejo v zavezah za povečevanje izdatkov za obrambo ter v težnji po posodobitvi vojsk in povečanju njihove bojne moči. Nato je oblikoval tudi strukturo sil VJTF za hitro posredovanje ob morebitni krizi. Priča smo tudi tesnejšemu povezovanju nevtralnih držav Finske in Švedske z Natom. Zasledimo analize, ki opozarjajo, da bo konflikt med Rusijo in »Zahodom« od Nata zahteval izboljšave spremljanja položaja, opozarjanja, obveščevalnih dejavnosti in sposobnosti odzivanja ob hitrem spreminjanju razmer (Johnson, 2015, str. 12). Potekajo tudi prizadevanja za povečanje sposobnosti strateškega premeščanja sil, če bi bilo treba.

Zaskrbljenost in hkrati težnje po okrepitvi obrambne sposobnosti so najbolj izrazite v vzhodnoevropskih, nordijskih ter baltskih državah. Poljska si prizadeva za posodobitev vojske, predvsem, da bi okrepila odvračanje. ${ }^{26} \mathrm{Za}$ dodatno oblikovanje rezervnih sil si prizadeva predvsem Češka, ki namerava vzpostaviti aktivno rezervo v obsegu nekaj tisoč izurjenih in motiviranih pripadnikov; torej hitro razpoložljivo in dobro pripravljeno rezervno strukturo (Military Balance 2016, str. 60). Med odzivi na spremenjene geopolitične razmere razen izjem ne najdemo ponovnega uvajanja vojaške obveznosti in oblikovanja množičnih vojsk.

Zamisli o ponovni uvedbi vojaškega roka srečamo v nekaterih evropskih državah. V Nemčiji za zdaj ostajajo na ravni razprave. Švedska in Litva sta edini ponovno

\footnotetext{
${ }^{25}$ O vprašanju (ne)poznavanja prihodnosti, povezanem z obrambnim načrtovanjem, glej na primer Gray, 2010, ter Jasper, 2009, str. 3 in 7.

${ }^{26}$ V ta namen načrtuje nakup letal F-16, posodobitev raketne protiletalske obrambe in nakup kopenskih raketnih sistemov.
} 
uvedli služenje vojaškega roka, vendar gre za rešitve, ki so drugačne kot v preteklosti. ${ }^{27}$ Litva je služenje vojaškega roka uvedla leta 2015, Švedska pa ga namerava leta 2018. V obeh primerih bo vojaški rok služil le del letnega nabornega kontingenta, ki bo izbran na podlagi lastnega interesa oziroma naključnega izbora. Na Švedskem bo vojaški rok na leto služilo 4000 mladih, v Litvi pa med 3500 in 4000. Gre torej za selektivni nabor. V obeh državah kot vzroka za uvedbo služenja navajajo spremembo geopolitičnih razmer in težave pri popolnjevanju vojaških dolžnosti v stalni sestavi, torej pomanjkanje poklicnih vojakov. Služenje bo trajalo devet mesecev v Litvi in od devet do enajst na Švedskem, kjer bo mogoče tudi za ženske. Omenjeno obdobje že lahko zagotovi dobro vojaško usposobljenost nabornikov. V obeh primerih se naborniki po služenju odločijo za službo v stalni sestavi ali za razporeditev v rezervo. Pomembna pri tem je težnja, da bi se posameznik po končanem vojaškem roku odločil za službo v vojski. V Litvi je tako na primer leta 2017600 nabornikov po služenju ostalo zaposlenih v stalni sestavi. ${ }^{28}$ Z uvedbo služenja vojaškega roka nobena izmed omenjenih držav bistveno ne povečuje skupnega obsega vojske ali spreminja razmerja med stalno sestavo in rezervo. Torej ne gre za vračanje h konceptu množične vojske, ki temelji na rezervi in mobilizaciji. ${ }^{29}$

Upravičeno je tudi vprašanje, ali lahko vse bolj prisotna »hibridizacija vojskovanja« pripelje do preobrata $\mathrm{v}$ transformaciji $\mathrm{v}$ smeri ponovnega vračanja množičnih naborniških vojsk. Zanesljivo oceno je težko dati že zato, ker je takih konfliktov malo in je posledično malo empiričnih podatkov. Ob spopadih v Ukrajini leta 2014 se je pokazalo, da je prav koncept ukrajinske naborniške vojske, dopolnjene z rezervo, ob pomanjkanju dobro usposobljenih vojaških enot skupaj z drugimi pomanjkljivostmi vodil do neuspeha. V primeru priključitve Krima k Rusiji, ki je potekala pod grožnjo precej močnejših ruskih sil in z zelo hitro, za Ukrajino vojaško zoperstavljanje pravzaprav sploh ni bilo realna možnost izbire. Večje vojaške pomanjkljivosti tedanje ukrajinske vojske so se pokazale pri konfliktu v Donbasu. Po ocenah analitikov ukrajinske vojaške sile, sestavljene pretežno iz nabornikov in rezervistov, niso bile kos upornikom, ki jih je prikrito vojaško podpirala Rusija. Za delovanje proti upornikom v urbanem okolju bi bile ustreznejše specialne sile. Pozneje je ustanavljanje novih prostovoljnih ukrajinskih enot v okviru nacionalne garde sicer privedlo do boljše motiviranosti pripadnikov, vendar je ostala težava nezadostne izurjenosti in opremljenosti (Reisinger in Goltz, 2014). ${ }^{30}$ Tudi ob

\footnotetext{
${ }^{27}$ V Skandinaviji in baltski regiji že iz preteklosti ohranjajo vojaško obveznost Danska, Estonija, Finska in Norveška.

${ }_{28}$ Uradna stran oboroženih sil Litve https://kariuomene.kam.lt/en/military_service.html in The Guardian, https:// www.theguardian.com/world/2017/mar/02/sweden-reintroduce-conscription-amid-rising-baltic-tensions.

${ }^{29}$ Litva ima 11.000 pripadnikov stalne sestave in 6700 pripadnikov rezerve, švedska vojska ima 15.300 pripadnikov stalne sestave, nima rezerve v klasičnem pomenu in razpolaga še z 22.000 pripadniki nacionalne garde (Home Guard) na visoki stopnji izurjenosti in pripravljenimi za takojšnjo uporabo v vseh nalogah vojske.

${ }^{30}$ Reisinger in Goltz (2014, str. 8-9) navajata, da je ukrajinska vojska štela 41.000 pripadnikov kopenskih sil, da pa jih je v resnici le 6000 dosegalo stanje ustrezne bojne pripravljenosti. Glede opreme, logistike in zaščite je ukrajinska vojska pokrivala le deset odstotkov potreb, velik del potreb pa so pokrivali s prostovoljnimi donacijami ali tako, da so si pripadniki oborožitev in opremo nabavljali sami. Tudi poznejša mobilizacija rezervistov je pokazala, da niso kos spopadu z lokalnimi milicami in da bolj kot ne še poslabšujejo stanje.
} 
notranjih konfliktih, kot je tisti na vzhodu Ukrajine, torej kaže, da naborniške in slabo pripravljene rezervne sile niso kos nalogam in da sta dobra organiziranost in izurjenost vojske pomembnejši od množičnosti.

Narava vojne se v sodobnosti korenito spreminja, zato si bo treba prizadevati za preseganje uveljavljenih pojmovanj in konceptov. Izkušnje iz preteklosti bodo verjetno izgubljale pomen, posebno pozornost bo treba nameniti vplivu novih dejavnikov. V tem smislu koncepti, ki so bili učinkoviti v preteklosti, ne bodo nujno učinkoviti tudi v prihodnosti. Mogoče je sklepati, da se bodo vojske v prihodnje razvijale v smeri večje tehnološke sofisticiranosti, da se ne bodo bistveno številčno povečevale, da bo najpomembnejša dobro usposobljena stalna sestava, rezervne sile pa bodo uporabne, kolikor bodo imele lastnosti tako imenovane aktivne rezerve, ki je dovolj usposobljena, da jo je mogoče hitro in učinkovito uporabiti. Vračanja h konceptu množične vojske, ki temelji na mobilizaciji, v Evropi ni več. Slovenski koncept VSR ne sledi navedenim transformacijskim trendom, zato tudi ne ponuja učinkovitih odgovorov na težave z zagotavljanjem vojaške varnosti. Če želi Slovenija povečati zmožnost za zagotavljanje vojaške varnosti, bosta pomembnejša razvoj in posodobitev stalne sestave SV, ki pa mora biti dopolnjena z usposobljeno aktivno rezervo, katere model je lahko sedanji koncept prostovoljne rezervne sestave, če bo ustrezno izpopolnjen in bo zagotavljal uporabnost v sodelovanju s stalno sestavo. ${ }^{31}$

Sklep V sodobnih vojskah je rezervna komponenta pomembna sestavina. Z zmanjševanjem vojsk in prevlado poklicnega modela je postala za učinkovitost vojske še pomembnejša, kar odraža tudi Natova politika glede rezerve. ${ }^{32}$ Transformacija vojsk obsega tudi transformacijo rezerve, s čimer se spreminjata njena struktura in vloga. Zmanjševanje obsega, dvig pripravljenosti za delovanje in sposobnosti za delovanje skupaj s stalno sestavo v vseh nalogah so temeljne značilnosti sodobne rezerve. Spremembe geopolitičnih razmer na vzhodu Nata ne vodijo v ponovno oživljanje konceptov vojske, temelječe na množičnosti in mobilizaciji.

V Sloveniji zamisli glede razvoja in organiziranja VSR ne sledijo tem trendom. Doktrina VSR se opira na preživet model množične vojske, ki temelji na vojaški obveznosti in mobilizaciji. Ob tem, ko nam je v procesu transformacije SV glede stalne sestave v določeni meri uspelo uveljaviti model »postmoderne«, poklicne, sodobnim zahtevam prilagojene vojske, nam to ni uspelo pri konceptualnih rešitvah glede rezerve. Ostajajo resni dvomi glede učinkovitosti VSR pri zagotavljanju obrambne sposobnosti Slovenije in glede zagotavljanja prispevka k zmogljivostim Nata. S sedanjo zamislijo glede VSR bo tudi težko doseči cilje Natove politike o vlogi rezerve. O obrambni sposobnosti države lahko realno razmišljamo samo ob

\footnotetext{
${ }^{3 I}$ Do zdaj je koncept pokazal številne pomanjkljivosti. Konec leta 2015 je SV za reševanje problematike migrantov vpoklicala 300 pripadnikov rezervne sestave. Vojaško službo je v začetku leta 2016 začelo izvajati manj kot 50 odstotkov vpoklicanih, izvedba vpoklica pa je opozorila na več težav glede statusa pripadnikov rezerve. Glej Osterman in Vegič, 2016: str. 220-221. O pomanjkljivostih izvajanja koncepta prostovoljne rezerve glej tudi Garb, 2016.

${ }^{32}$ MC 0441/2 - NATO Framework Policy on Reserves.
} 
upoštevanju članstva v Natu, zato je neskladje med varnostnopolitičnimi cilji države in zamislijo glede VSR še večje.

V zadnjih letih se je SV res spoprijemala s precejšnjimi težavami glede modernizacije in razvoja zmogljivosti, vendar na VSR ne bi smeli gledati kot na alternativno rešitev, ki lahko kompenzira težave glede doseganje razvojnih ciljev SV. V zadnjem času lahko zasledimo prepričanje, da bi morali SV razumeti kot celoto, ki obsega tudi VSR. ${ }^{33}$ Tako prepričanje ustvarja napačen vtis o obrambnih zmogljivostih države, ni skladno s sodobnim razumevanjem vojske in glede na negotovo izvedljivost koncepta VSR ustvarja na področju obrambnega načrtovanja neskladje med deklariranimi in res dosegljivimi cilji.

Zamisel o VSR ne izhaja iz vojaških krogov. Nastala je v kontekstu oblikovanja širše nacionalnovarnostne politike, bi pa bilo pričakovati natančnejšo presojo pomembnosti te zamisli z vojaškega vidika. Ob tem, ko sicer zasledimo kritične razprave posameznih vojaških strokovnjakov o tej zamisli, ${ }^{34}$ celovita presoja še ni bila opravljena. Hkrati je zamisel o VSR vse bolj vključena v planske dokumente na področju obrambe in razvoja SV. Ob pomanjkanju presoje vojaške pomembnosti te zamisli lahko to vodi v napačne ocene glede lastnih zmogljivosti. Te so kritični element za realno obrambno načrtovanje.

\section{Literatura}

1. Doktrina vojaške strateške rezerve Republike Slovenije, št. 80300-2/2012/5 z dne 25. 10. 2012. Ministrstvo za obrambo RS, Ljubljana.

2. Dunnigan, F. James, 2003. How to Make War. Quill, New York.

3. FFAO - Framework for Future Alliance Operations, 2015. NATO.

4. FFAO Workshop, 2016. Delavnica na temo priprave novega Natovega dokumenta Framework for Future Alliance Operations, 26.-30. september 2016. Bydgoszcz, Poljska.

5. Garb, M., 2016. O rezultatih raziskav o PPRS - razprava na posvetu. V Šteiner, A., (ur.) Vloga rezerve pri zagotavljanju vzdržljivosti obrambno-varnostnih sistemov Slovenije, str. 296-297. Državni svet RS, Ljubljana.

6. Gerson, M. S., 2009. Conventional Deterrence in the Second Nuclear Age. Parameters, Autumn 2009.

7. Gray, C. S., 2010 (Summer). War-Continuity in Change and Change in Continuity. Parameters.

8. Haltiner, K., W., Szvircsev Tresch, T., 2005. The Decline of Conscription in Europe. V Bebler, A., (ur.) Sodobno vojaštvo in družba. Fakulteta za družbene vede, Ljubljana.

9. Izhodišča MO RS v zvezi z možnostjo ponovne uveljavitve obveznega služenja vojaškega roka, Ljubljana, 2017.

10. Jasper, S., (ed.), 2009. Transforming Defense Capabilities: New Approaches for International Security. Lynne Reinner Publishers, Boulder, London.

\footnotetext{
33 O tem glej na primer Žnidaršič, 2016, str. 134.

34 Več razprav je objavljenih v zborniku s posveta Vloga rezerve pri zagotavljanju vzdržljivosti obrambnovarnostnih sistemov Slovenije. Za razumevanje problematike je treba posebej opozoriti na prispevke avtorjev Ivana H. Kukca, Renata Petriča, Viktorja Potočnika, Antona Šteinerja in Francija Žnidaršiča.
} 
11. Jelušič, L., 2016. Ponovna uvedba naborništva - da ali ne? V Šteiner, A., (ur.) Vloga rezerve pri zagotavljanju vzdržljivosti obrambno-varnostnih sistemov Slovenije. Državni svet RS, Ljubljana.

12. Johnson, D., 2015. Russia's Approach to Conflict-Implications for NATO's Deterrence and Defence. Research Paper no 111. NATO Defence College, Rome.

13. Kukec, I. H., 2016. Slovenski koncept vojaške strateške rezerve-iluzija ali realnost. $V$ Šteiner, A., (ur.) Vloga rezerve pri zagotavljanju vzdržljivosti obrambno-varnostnih sistemov Slovenije. Državni svet RS, Ljubljana.

14. Lasconjarias, G., 2013. Send the Reserve! New Ways to Support NATO through Reserve Forces. Research Paper no. 99. NATO Defence College, Rome.

15. Lind, W. S., 1989. The Changing Face of War: Into the Fourth Generation. Marine Corps Gazette, 73/10.

16. Malešič, M., 2003. A Conscript Army or an All-Volunteer Force? A Contribution to the Discussion in Slovenia. VMalešič, M., (ed.) Conscription vs. All-Volunteer Forces in Europe. Nomos Verlagsgesellschaft, Baden-Baden.

17. Malešič, M., 2003a. The discussion on Conscript Army and All-volunteer Forces in Europe. V Callaghan, J., Kernic, F., (eds.) Armed Forces and International Security. LIT Verlag, Münster.

18. MC 0441/2 - NATO Framework Policy on Reserves. www.act.nato.int/images/stories/ structure/reserve/mc_0441_2_eng.pdf.

19. Military Balance, različni letniki. International Institute for Strategic Studies. London.

20. Moskos, C., 2000. The Postmodern Military-Armed forces after the Cold War. Oxford University Press, New York, Oxford.

21. Obrambna strategija RS, 2012. Ministrstvo za obrambo RS, Ljubljana.

22. Osterman, A., Vegič, V., 2016. Izzivi Slovenske vojske v razvojni perspektivi. V Šteiner, A., (ur.) Vloga rezerve pri zagotavljanju vzdržljivosti obrambno-varnostnih sistemov Slovenije. Državni svet RS, Ljubljana.

23. Petrič, R., 2016. Slovenska vojska na prelomu. V Šteiner, A., (ur.) Vloga rezerve pri zagotavljanju vzdržljivosti obrambno-varnostnih sistemov Slovenije. Državni svet $R S$, Ljubljana.

24. Podvršnik, M., Pograjc, B., 2016. O teoriji in praksi vojaške rezervne sestave. V Šteiner, A., (ur.) Vloga rezerve pri zagotavljanju vzdržljivosti obrambno-varnostnih sistemov Slovenije. Državni svet RS, Ljubljana.

25. Potočnik, V., 2016. Četrta generacija vojskovanja. Sodobni vojaški izzivi, 18/4.

26. Prebilič, V., Juvan, J., 2014. Mladi, domoljubje in nacionalna varnost: vojska kot steber domoljubnih struktur. Sodobni vojaški izzivi, 16/1.

27. Reisinger, H., Goltz, A., 2014. Russia's Hybrid Warfare. Rasearch Paper, NATO Defence College.

28. ReSDPROSV25, 2010 - Resolucija o splošnem dolgoročnem programu razvoja in opremljanja Slovenske vojske do leta 2025.

29. SFA - Strategic Foresight Analysis, 2013 NATO.

30. SOPR 2016-2020, 2016 - Srednjeročni obrambni program Republike Slovenije 20162020.

31. Statistični urad RS, 2017. http://www.stat.si/StatWeb/News/Index/6799 (24. 8. 2017).

32. Svete, U., 2016. Sodobno (geo)strateško okolje in zaton tradicionalne nacionalne države. V Šteiner, A., (ur.) Vloga rezerve pri zagotavljanju vzdržljivosti obrambno-varnostnih sistemov Slovenije. Državni svet RS, Ljubljana.

33. Šteiner, A., 2016. Tipologija rezerve v sodobnih razmerah. V Šteiner, A., (ur.) Vloga rezerve pri zagotavljanju vzdržljivosti obrambno-varnostnih sistemov Slovenije. Državni svet RS, Ljubljana. 
34. Šteiner, A., 2016a. Primeri zagotavljanja sposobnosti za vojaško strateško rezervo. V Šteiner, A., (ur.) Vloga rezerve pri zagotavljanju vzdržljivosti obrambno-varnostnih sistemov Slovenije. Državni svet RS, Ljubljana.

35. Thornton, R., 2015. The Changing Nature of Modern Warfare: Responding to Russian Information Warfare. RUSI Journal, 160/št. 4.

36. Transforming the British Army, 2013. www.army.mod.uk/documents/general/Army2020 Report_v2.pdf (4.9. 2017).

37. Young, Thomas-Durell, 2016. The Challenge to Defense Reform in Central/Eastern Europe, with Reference to Slovenia. Sodobni vojaški izzivi, 18/4.

38. Zapfe, M., 2015. NATO's »Spearhead Force«. Center for Security Studies, Zurich. http:// www.css.ethz.ch/cssanalysen (20.8. 2017).

39. Žabkar, A., 2005. Izzivi tretjega tisočletja in oborožene sile. V Bebler, A., (ur.) Sodobno vojaštvo in družba. Fakulteta za družbene vede, Ljubljana.

40. Žnidaršič, F., 2016. Nastajanje in uveljavljanje rešitev za vojaško strateško rezervo RS. $V$ Šteiner, A., (ur.) Vloga rezerve pri zagotavljanju vzdržljivosti obrambno-varnostnih sistemov Slovenije. Državni svet RS, Ljubljana. 